\title{
Geopolítica e energia na região do Cáspio
}

\section{Geopolitics and energy in the Caspian region}

Rev. Bras. Est. Def. v. 5, $n^{\circ} 1$, jan./jun. 2018, p. 251-271

BRUNA BOSI MOREIRA

\section{INTRODUÇÃO}

Relativamente desconhecida, especialmente no Brasil, a região do Cáspio, pelas particularidades que a caracterizam, oferece valioso ponto de partida para a reflexão sobre o ressurgimento da geopolítica. No nível internacional, as mudanças subsequentes ao fim da Guerra Fria foram da alteração do mapa mundial à crença no "fim da história", levando ao entendimento de que a geografia havia sido superada. Ao longo da década de 1990, porém, já havia sinais de contradições nesta interpretação e, em 2001, com o 11 de setembro e a resposta a este evento, passamos a nos deparar mais intensamente com a geografia e com todas as implicações políticas que dela advêm. Atualmente, a geopolítica tem aparecido cada vez mais em análises de relações internacionais, fato motivado pela tentativa de explicar questões como os conflitos envolvendo o Mar do Sul da China, a guerra na Síria e a maior assertividade russa - a qual, inclusive, culminou com a alteração do mapa eurasiático a partir da anexação da Criméia.

Essa linha de raciocínio leva ao entendimento de que o uso da geopolítica, enquanto abordagem para a compreensão das relações internacionais e enquanto guia para a política externa das grandes potências, acompanha os acontecimentos internacionais, ora estando em voga, ora não. No nível regional, contudo, nem sempre tem sido assim. A região do Cáspio é um dos exemplos que desafiam o entendimento de que, em algum momento, a geopolítica caiu em desuso. Pelo contrário, a região tem sido foco do pensamento geopolítico desde Mackinder até os nossos dias, tornando-se parte do que Agnew denomina de "imaginação geopolítica moderna”, um conjunto de representações geográficas, retóricas e práticas que tem pautado a política mundial.

Bruna Bosi Moreira - Doutoranda em Relações Internacionais na Universidade de Brasília. 
O próprio nome pelo qual a atual conjuntura regional tem sido tratada como o Novo Grande Jogo ${ }^{1}$ - remete ao ressurgimento de antigas rivalidades nesta mesma região. Foram, por sua vez, essas rivalidades do século XIX - o Jogo original -, que consolidaram a própria Geopolítica, enquanto disciplina legitimadora do imperialismo britânico e russo daquela época.

Este artigo objetiva, pois, explicitar como a região do Cáspio está atrelada à própria geopolítica. Embora diversas sejam as características históricas e geográficas da região que explicam tal relação, a mais evidente parece estar relacionada aos recursos energéticos do Cáspio e ao interesse que estes despertam nas grandes potências, especialmente em Rússia, Estados Unidos e China. O foco deste artigo será, portanto, na geopolítica envolvendo os hidrocarbonetos da região.

Na primeira seção, a região é apresentada, a fim de situar o leitor em área geográfica relativamente desconhecida, especialmente no Brasil. Além disso, pretende-se justificar também o recorte temático, caracterizado pelo enfoque nos recursos energéticos. Na segunda parte, o foco é a discussão acerca da geopolítica, seu ressurgimento nas Relações Internacionais (RI) e sua permanente presença no Cáspio.

\section{O ELDORADO ENERGÉTICO}

Coração da Eurásia, o mar Cáspio consiste na maior porção fechada de água salgada do mundo, sendo delimitado pelas fronteiras de cinco Estados - Rússia, Cazaquistão e Turcomenistão (na Ásia Central), Azerbaijão (no Cáucaso) e Irã (no Oriente Médio). Sob comando alternado do Império Russo e da URSS, foi apenas na década de 1990 que os países da Ásia Central e do Cáucaso ganharam sua independência. Assim, especialmente durante o período da Guerra Fria, a região permaneceu inacessível ao chamado Ocidente, pois se tratava de parte territorial da superpotência inimiga. Com o advento do novo século e das profundas transformações que o acompanharam, o mundo assistiu a intenso processo de reformulação de fronteiras e de surgimento de novos países no centro da Eurásia.

Um dos resultados dessa metamorfose geopolítica foi a produção de grande euforia no Ocidente, incentivada especialmente pela expectativa de que o Cáspio seria o grande Eldorado energético, rico em petróleo e gás natural. Durante a década de 1990, estimativas extremamente otimistas sobre as reservas energéticas do Cáspio incentivaram governos e empresas a se fazerem presentes na região e chegaram a apontar a Ásia Central como potencial alternativa ao fornecimento dos países do Oriente Médio. Naquela época, a própria CIA ajudou a construir a ideia de que o Cáspio equivaleria a uma nova Arábia Saudita (Adams 2004) e, em 1998, Dick 
Cheney afirmou: "não consigo pensar em um tempo em que uma região emergisse tão repentinamente para se tornar tão estrategicamente significativa quanto o Cáspio" (Cohn 2000, tradução nossa).

Essa ideia era atraente a um Ocidente pós-choques do petróleo, para o qual o conceito de segurança energética implicava a diversificação e a maximização da oferta global de energia. Aos poucos, porém, dificuldades começaram a surgir, arrefecendo as expectativas de empresas e de Estados. A profundidade e a alta pressão a que estavam submetidas muitas das reservas, além dos problemas corrosivos, característicos do tipo de petróleo da região (Akiner 2004, 9), tornavam difícil a exploração e altos os custos de produção, ainda que as reservas fossem significativas.

Além disso, a estrutura era precária e limitada, pois fora herdada da extinta URSS, na qual as rotas de transporte e distribuição de energia da região levavam exclusivamente à Rússia. Por isso, inserir o Cáspio no mercado energético global demandava investimentos custosos, necessários à descoberta de novas reservas e à construção de gasodutos e oleodutos que possibilitassem a ampliação da rede de distribuição. Assim, as dificuldades também representavam oportunidades, especialmente para os Estados Unidos e países europeus, que possuíam o know-how e o capital necessários para o desenvolvimento do potencial energético na região.

Energia, portanto, constituía-se como a espinha dorsal dos projetos envolvendo o Cáspio naquela época. Na realidade, desde o início da exploração das reservas em Baku, ainda nos anos 1870, e com a abertura da região ao investimento privado, a exploração do petróleo se tornou o principal elo de ligação da região com o mundo (Akiner 2004, 3). Assim, desde os primórdios da exploração do petróleo, a relevância da região tem sido historicamente atrelada a seu potencial energético, seja pelas reservas onshore $e^{2}$ dos países limítrofes, seja pelas reservas offshore ${ }^{3}$ do mar em si.

Mesmo diante de inúmeros motivos para justificar o interesse internacional pelo mar Cáspio, a literatura acaba recorrendo quase sempre à energia como fator principal, o que surpreende quando se confrontam as estatísticas. Porém, para que seja possível analisar os dados com rigor metodológico, cabe, antes, esclarecer o que significam os termos (i) Mar Cáspio, (ii) bacia do Mar Cáspio e (iii) região do Mar Cáspio ou da bacia do Mar Cáspio.

$\mathrm{O}$ primeiro refere-se à porção de água amplamente conhecida como mar, mas que em realidade é um lago. As estatísticas energéticas referentes a ele são, por isso, apenas de recursos offshore. O segundo, embora utilizado no singular, refere-se a um conjunto de quatro bacias que englobam o Mar Cáspio em si, partes dos cinco Estados limítrofes e ainda uma pequena parcela do Uzbequistão. Já quando se fala em região, extrapolam-se os limi- 
tes geológicos da bacia, podendo incluir-se na análise os países limítrofes em sua totalidade, ou seja, não apenas as partes de seus territórios que se localizam sob a bacia. Essa distinção é importante quando se analisam as estatísticas, pois estas variam muito conforme se inclua ou não os países em sua totalidade ou apenas as parcelas territoriais especificamente localizadas na bacia.

A Rússia, por exemplo, possui apenas uma pequena faixa de seu vasto território sobre a bacia. No entanto, as reservas do país em sua totalidade o colocam dentre os principais detentores, produtores e exportadores de hidrocarbonetos do mundo. $\mathrm{O}$ mesmo vale para o Irã em termos de reservas. ${ }^{4}$ Ademais, ao falar do Cáspio enquanto região, pode-se ampliar a abrangência desta para além dos países limítrofes, incluindo também outros Estados da Ásia Central e do Cáucaso, como o próprio Uzbequistão já citado, Quirquistão, Tajiquistão, Geórgia e Armênia.

Por termos energia como ponto de partida para explicar uma dinâmica mais ampla, considera-se necessário ir além dos limites geológicos da bacia e, portanto, incluir os dados dos cinco países limítrofes e do Uzbequistão ${ }^{5}$ em sua totalidade. Essa escolha se justifica porque não se trata de um estudo geológico das reservas energéticas da bacia em si, mas sim da dinâmica política e de segurança que está relacionada à capacidade energética dos países da região. A natureza do trabalho e seus objetivos exigem, portanto, essa delimitação mais ampla. ${ }^{6}$

A U.S. Energy Information Agency (EIA 2013) estima que, entre reservas provadas e prováveis, a capacidade do Mar Cáspio, isto é, reservas offshore, seja de 19,6 bilhões de barris de petróleo (BB) e de 292 trilhões de pés cúbicos (Tcf) de gás natural. Colocando-se essa informação em perspectiva, a Arábia Saudita sozinha possui uma reserva de petróleo comprovada de 268 $\mathrm{BB}$ e apenas o Catar possui uma reserva comprovada de gás natural de 872 Tcf (EIA 2015). Portanto, olhar somente para o mar Cáspio em si não é suficiente para justificar o grande frenesi criado em relação a seus recursos. Essa incongruência entre o que mostram os dados e o que se anunciava como grande alternativa energética nos anos 1990 fica ainda mais evidenciada quando se tem em conta que esses números referentes ao mar Cáspio dizem respeito não apenas às reservas provadas, mas também às prováveis.

De fato, o elemento "prováveis" é fundamental para compreender a expectativa criada em torno das reservas do mar Cáspio, pois diversos fatores dificultavam - e, ainda que em menor grau, continuam dificultando - que se soubesse mais precisamente sua real capacidade. Um dos entraves foi a falta de um status legal, o qual permaneceu sem resolução até agosto de 2018. Até a década de 1990, havia apenas dois países delimitando essa porção aquífera - Rússia/URSS e Irã, os quais estabeleceram um regime 
de condomínio, ou seja, de uso e soberania conjunta. Com a formação dos novos Estados, estes não aceitaram o modelo de condomínio, o qual desagradava também as empresas interessadas em explorar os recursos do Cáspio. A partir daí instaurou-se longo debate sobre como a delimitação de zonas exploratórias deveria ocorrer.

Não obstante os avanços (ainda em 2003, por exemplo, Rússia, Cazaquistão e Azerbaijão assinaram um acordo delimitando suas fronteiras marítimas no Cáspio), ainda havia questões a serem resolvidas. Um dos principais pontos de divergência vinha do Irã, que insistia que os cinco Estados deveriam ter controle sobre a mesma porcentagem do mar, o que resultaria em $20 \%$ para cada país, contra os $12 \%$ que caberiam ao Irã caso a divisão fosse proporcional (Kucera 2014).

Importante avanço na resolução desta questão ocorreu em 2014, durante o IV Caspian Summit, no qual os países conseguiram acordar sobre a delimitação de áreas marinhas, fundo do mar, recursos do subsolo e as regras e princípios de navegação e pesca. Também ficou decidido que a maior parte do mar Cáspio permanece de uso comum dos cinco Estados (Yakovenko 2014). Esse foi o ponto de partida para que um rascunho da convenção intitulada "Convention on the Legal Status of the Caspian Sea" fosse feito. Em maio de 2018, um encontro de ministros do exterior em Astana preparou a pauta para o V Caspian Summit (Republic of Kazakhstan 2018), que ocorreu em agosto do mesmo ano, também no Cazaquistão. Nessa ocasião, a Convenção foi finalmente assinada pelos cinco Estados que margeiam o lago.

A falta de definição a respeito do status legal do Cáspio foi, até agora, um fator limitador de sua exploração e do desenvolvimento de infraestrutura, contribuindo para a expectativa internacional do potencial da região, ou seja, das reservas prováveis, o que inclui não apenas a existência de recursos em si mas também a viabilidade de sua exploração. Assim, ainda que os custos de produção fossem mais altos que no Golfo Pérsico, as projeções do potencial energético do Cáspio estimulavam a continuidade dos investimentos, pois havia também a expectativa de que a tecnologia poderia diminuir esses custos. Ainda hoje, as estimativas sobre a quantidade de petróleo e gás impulsionam os investidores e se aplicam também às reservas onshore da bacia, visto que os especialistas acreditam que apenas uma parte do total das reservas tenha de fato sido encontrada (Kubicek 2013, 172). Em relação aos recursos totais dos seis países, tem-se de, acordo com a Tabela 1, a seguir: 
Tabela 1

Reservas provadas onshore dos países da região do Cáspio

\begin{tabular}{|c|c|c|c|c|c|c|c|c|}
\hline \multicolumn{2}{|c|}{} & Rússia & Cazaquistão & Uzbequistão & Turcomenistão & Irã & Azerbaijão & Total \\
\hline \multirow{2}{*}{ Capacidade } & $\begin{array}{c}\text { Petróleo } \\
(\mathrm{BB})\end{array}$ & 80 & 30 & 0,6 & 0,6 & 158 & 7 & $\mathbf{2 7 6 , 2}$ \\
\cline { 2 - 9 } & $\begin{array}{c}\text { Gás } \\
\text { (Tcf) }\end{array}$ & 1688 & 85 & 65 & 265 & 1201 & 35 & $\mathbf{3 3 3 9}$ \\
\hline
\end{tabular}

Fonte: Elaborada pela autora a partir de dados de 2015 da U.S. Energy Information Agency.

Em sua totalidade, essas reservas são bastante significativas, especialmente se considerarmos a baixa produtividade da região, o que aponta para seu potencial futuro. Referindo-se ao petróleo, Klare $(2002,85)$ afirma que o mais notório é que a produção no Cáspio tende a aumentar nos próximos anos, enquanto a tendência em outras áreas é de diminuição. Kubicek (2013, 172) argumenta no mesmo sentido, ao afirmar que, embora as alusões ao Cáspio como um novo Golfo Pérsico possam ter sido exageradas, é preciso ter em conta que as reservas potenciais de petróleo da região são maiores que as reservas da Venezuela, Nigéria, Líbia e Noruega juntas e que, portanto, o que está em questão é sim uma grande contribuição ao mercado energético mundial.

Não obstante, ainda que o potencial energético da área seja fundamental para explicar o interesse internacional despertado pelo Cáspio, ele não é suficiente para justificar a motivação das grandes potências em atuar na região. Afinal, a importância da região ganha dimensão global também por outros fatores além da questão energética. A instabilidade política dos países recém-criados, o potencial aprofundamento do fundamentalismo islâmico na região, o tráfico de drogas, a falta de infraestrutura, os potenciais conflitos étnicos, a falta de governança entre os próprios Estados locais com relação à bacia e os regimes políticos desses Estados também contribuíram para que o Cáspio entrasse na agenda de segurança internacional.

Pode-se, é claro, observar que o interesse Ocidental em energia faz com que se priorizem algumas zonas de instabilidade enquanto foco de preocupação, em detrimento de outras. Afinal, não eram poucas as áreas de instabilidade no mundo nos anos 1990; porém, para os EUA e seus aliados era importante garantir que as potências locais, especialmente Rússia e Irã, não bloqueassem seu acesso às reservas do Cáspio. Nas palavras de Grygiel (2006, 30, tradução nossa), por serem desigualmente distribuídos, “os recursos fazem algumas regiões estrategicamente mais vulneráveis que outras. [...] o que acontece nessas e para essas regiões tem um impacto nas vidas de outros Estados, que consequentemente vão prestar mais atenção, militarmente ou diplomaticamente, a elas”. 
Assim, a dinâmica regional está em grande medida pautada pela atuação de potências externas. Contudo, isso não significa caracterizar a região como um grande vácuo. Pelo contrário, os países locais inclusive se aproveitam da disputa entre as grandes potências para barganhar a favor de seus próprios interesses, influindo, portanto, e até mesmo direcionando, a dinâmica da região:

As relações entre os cinco [países] litorâneos do Cáspio são marcadas por constantes mudanças e alianças temporárias de Estados para ganhar apoio para algumas demandas e bloquear outras. A razão central para essa situação são as diferenças nos interesses e nas providências tomadas por atores externos (Naumkin 2001, 135, tradução nossa).

Além disso, embora delimitado apenas pelos cinco países, a compreensão do Cáspio exige que se observe seu entorno. Justamente por ser fechado, para escoar a produção de hidrocarbonetos é preciso passar por terra, o que envolve um complexo emaranhado de gasodutos e relações políticas que ligam os Estados desta região. Além da questão energética, uma delimitação mais ampliada da região ajuda a compreender a importância geopolítica do Cáspio, pois a área se encontra em local privilegiado do globo, ao conectar Europa, Ásia e Oriente Médio.

Dessa forma, considerando-se as características da região apresentadas até aqui, um estudo da geopolítica parece necessário para compreender a região assim como, de certa forma, a região parece ser importante para o entendimento da evolução histórica da própria Geopolítica enquanto disciplina. Esse será o foco de discussão da próxima seção.

\section{A GEOPOLÍTICA E O CÁSPIO}

Carregada de controvérsias, a Geopolítica parece ter ressurgido recentemente enquanto abordagem para explicar os principais focos de tensão das relações internacionais contemporâneas, embora muitas vezes não haja consenso sequer sobre o que o termo significa. ${ }^{7} \mathrm{O}$ enfoque geopolítico passou as últimas décadas em segundo plano, ofuscado pelas ideias de multipolaridade e de interdependência que ganharam destaque a partir dos anos 1990, quando a chamada Nova Ordem Mundial foi inaugurada. A abordagem, intensamente utilizada até o período da Guerra Fria, se tornou praticamente obsoleta diante dos avanços em termos de cooperação e de governança globais alcançados nas últimas décadas, bem como à predominância das questões de natureza econômica nas relações internacionais.

Não obstante, se seu retorno às RI em geral é recente, na região do Cáspio essa abordagem nunca deixou de imperar enquanto fator explicativo 
para a dinâmica regional. Por isso, embora à primeira vista não pareça relevante recuperar pensadores a serviço do imperialismo do início do século $\mathrm{XX}$ - ou seja, recuperar um contexto de uma época específica -, uma observação mais cuidadosa de influentes autores contemporâneos aponta para o quanto a policy ainda é fortemente influenciada por aquelas ideias, ainda que revestidas de maior cuidado para evitar cair em armadilhas morais.

Além da influência e apelo que a Geopolítica possui para governantes, estudá-la academicamente também se reveste de particular importância no caso dos recursos energéticos do Cáspio. $\mathrm{O}$ fato de estarem parte offshore e parte em países sem acesso a mar faz com que a viabilidade comercial dos hidrocarbonetos da região, especialmente o gás natural, dependa de oleodutos e gasodutos. O problema é que esses dutos passam por territórios externos aos dos países detentores dos recursos, formando uma complexa rede, cujas implicações políticas têm sido desde muito tempo centrais para compreender a dinâmica regional. Assim, não surpreende que a Geopolítica continue sendo basilar em trabalhos acadêmicos recentes ${ }^{8} \mathrm{e}$ mesmo em policy papers de importantes think tanks, ${ }^{9}$ que possuem marcada influência em governos.

Mas para falarmos em ressurgimento é preciso que compreendamos primeiramente em que momento e contexto essa abordagem teria sido abandonada. Para Kaplan (2013), a ilusão de que a geografia não importava mais, podendo ser superada, veio com a queda do muro de Berlim, cujo significado simbólico foi reforçado pelo grande idealismo da época que levava até mesmo a crer no "fim da História”, conforme defendido por Fukuyama.

A tese de Kaplan (2013) é a de que estamos vivendo a "vingança da geografia”, ciclo subsequente ao da derrota da geografia, que teria marcado a primeira década do pós-Guerra Fria. Assim, o 11 de setembro de 2001 e os acontecimentos que o sucederam teriam, pois, despertado novamente a consciência dos limites impostos pela geografia:

Fomos devolvidos, assim, aos princípios mais fundamentais da existência humana, em que, no lugar do aperfeiçoamento contínuo do mundo que havíamos antes vislumbrado, o que aceitamos foi o embate seguinte pela sobrevivência e, por associação, as severas limitações com que a geografia nos onerou em lugares como a Mesopotâmia e o Afeganistão (Kaplan 2013, 30).

Dessa forma, retomar a Geopolítica como abordagem explicativa para entender a dinâmica envolvendo os recursos da região não significa concordar com seus expoentes clássicos, intimamente ligados às políticas imperialistas dos Estados a que serviam, muito menos tomá-la como fator determinante do destino do Cáspio. A intenção de compreender o significado 
da abordagem se deve ao fato de que esta, desde o início do século passado até os dias atuais, tem sido recorrente nos trabalhos sobre a região. Assim, o primeiro passo nesse esforço é compreender o significado do termo.

Embora não tenha sido o primeiro a utilizar a palavra "geopolítica", ${ }^{10}$ o britânico Halford Mackinder foi o grande impulsionador dessa abordagem, e suas ideias ajudaram a justificar o interesse e o avanço dos Impérios Britânico e Russo na Eurásia na virada do século XIX para o XX - o Grande Jogo original. Sua ideia central era a de que o heartland eurasiano composto pela Ásia Central - compreenderia a região pivô do mundo e, por isso, seu controle seria fundamental para comandar o globo (Mackinder 1904; 1919).

Outro expoente da geopolítica clássica é Nicholas Spykman, que também focou parte de sua obra na região da Eurásia. No entanto, para este acadêmico, o centro do poder mundial não estava no heartland mas sim em sua periferia, que ele chamou de rimland - espécie de zona intermediária entre o poder terrestre e o marítimo. Spykman compreendia o rimland como a periferia do heartland mackinderiano, ou seja, seu entorno, o qual seria fundamental por sua característica marítima. Para Kaplan (2013, 98), ambos estão, em essência, se referindo à mesma tese, pois, para Mackinder, o heartland seria fundamental para conquistar o rimland, cujo poder marítimo seria basilar para dominar o mundo.

Ainda que sejam resultado de um contexto histórico específico, esses conceitos continuam sendo empregados por autores contemporâneos, muitos dos quais exercem importantes cargos em think tanks influentes e mesmo em governos, especialmente nos EUA, onde a relação da policy com a Academia é significativa. ${ }^{11}$ Dessa forma, essas teses clássicas, por mais inadequadas que soem, parecem fazer parte do que Agnew (2003) conceitua como "imaginação geopolítica moderna", composta por teorias e práticas da política mundial:

Essa imaginação geopolítica tem por longo tempo enquadrado a política mundial em termos de um abrangente contexto global no qual Estados competem por poder fora de suas fronteiras, ganham controle (formalmente e informalmente) sobre regiões menos modernas (e seus recursos) e ultrapassam outros grandes Estados em uma busca mundial por primazia global (Agnew 2003, 1, tradução nossa).

Brzezinski (1997), por exemplo - que foi conselheiro de segurança nacional do governo de Jimmy Carter entre 1977 e 1981 - escrevendo já na segunda metade da década de 1990 em um contexto pós-Guerra Fria, parece alimentar essa "imaginação", ao desenvolver seu pensamento à moda dos clássicos. Em seu The Grand Chessboard, Brzezinski entende a Eurásia 
como o prêmio geopolítico central para os EUA. Para ele, que foi um dos grandes formuladores da política externa norte-americana, a primazia global de Washington dependia da preponderância do país na região, a qual considera "geopoliticamente axial" (1997, 31, tradução nossa).

Claramente retomando conceitos mackinderianos do início do século passado, ${ }^{12}$ Brzezinski afirma que "um simples olhar para o mapa também sugere que o controle da Eurásia ocasionaria quase automaticamente a subordinação da África, tornando o Hemisfério Ocidental e a Oceania geopoliticamente periféricos ao continente central do mundo" (1997, 31, tradução nossa). Se, em um primeiro momento, pode parecer que suas ideias estão presas ao passado, vale ressaltar que, em 2007, Obama afirmou em discurso que Brzezinski era "um de nossos mais destacados acadêmicos" e "um de nossos mais destacados pensadores” (Obama 2007).

Assim, também pautado pela concepção geopolítica do mundo, Brzezinski (1997) entende que os assuntos mundiais ainda são dominados pela competição baseada no território, o que torna a posição geográfica o ponto de partida para a definição de prioridades do Estado. Dessa forma, para o autor, “[ [...] quanto maior for seu poder militar, econômico e político, maior será o raio, além de seus vizinhos imediatos, dos interesses geopolíticos vitais, da influência e do envolvimento daquele Estado" (Brzezinski 1997, 38, tradução nossa). Essas ideias, portanto, continuam ocupando a imaginação geopolítica moderna, a qual, segundo Agnew (2003), ainda domina a condução da política mundial, servindo à significação e à racionalização de práticas das elites políticas. Compreender seu significado parece, pois, fundamental.

Para Kaplan (2013, 62), a geopolítica é o “[...] estudo do ambiente externo com que cada Estado se depara ao traçar sua própria estratégia ambiente que envolve a presença de outros Estados, também lutando pela sobrevivência e por vantagens”. Assim, na concepção deste autor, a geopolítica está intimamente relacionada à política externa e ao interesse nacional dos Estados além de suas fronteiras. Foi com esse mesmo entendimento que, segundo Brzezinski (1997, 37, tradução nossa), Napoleão teria dito que "conhecer a geografia de uma nação era conhecer sua política externa”.

Klare explica o contexto competitivo envolvendo grandes potências e a região do Cáspio também em termos da geopolítica. $\mathrm{O}$ autor compreende o conceito com sendo "a rivalidade entre potências desejosas de controlar territórios, recursos naturais, acidentes geográficos vitais [...] e outros pontos econômica ou militarmente privilegiados" (Klare 2006, 223, tradução nossa).

Mais contemporâneo e, de certa forma, mais crítico das abordagens clássicas tradicionais, Agnew (2003, 1), assim como Kaplan, se utiliza do 
11 de setembro como marco temporal. Para o autor, a partir dessa data temos um quadro em que os EUA e seus adversários participam de um jogo global por controle e influência, fruto também da "imaginação geopolítica moderna”.

Segundo Agnew, o termo geopolítica tem sido utilizado para tratar do estudo das representações geográficas, retóricas e práticas que sustentam a política mundial. $\mathrm{O}$ autor parte do ressurgimento do conceito e de seus variados usos atuais para propor ao termo um significado mais específico: "exame das suposições, designações e entendimentos geográficos que entram na elaboração da política mundial" a fim de compreender "como sucedeu que as perspectivas de um Estado em relação a outros eram vistas em relação às condições globais, que eram vistas como impondo limites e definindo possibilidades para o sucesso de um Estado na arena global" (Agnew 2003, 5, tradução nossa).

Entrando no campo mais específico da energia, Fuser $(2013,87)$ afirma que há duas lógicas concomitantes que explicam a importância do petróleo, uma econômica e outra estratégica. Enquanto a primeira refere-se ao recurso como insumo e envolve investimentos relacionados ao marco econômico-financeiro liberal, a segunda pauta-se por sua escassez e má distribuição, além de ser uma fonte não renovável e fundamental para a segurança e bem-estar estatal.

Essa última lógica pode ser ampliada também para o gás natural, cuja dimensão estratégica parece ter peso ainda maior do que o petróleo quando se considera a alta regionalização de seus mercados, e o fato de que este recurso ainda não é uma commodity. Como consequência, o gás natural não se integra ao raciocínio frequentemente aplicado ao petróleo, de que o mercado é força reguladora suficientemente capaz de relativizar o aspecto geopolítico e dirimir o caráter conflitivo envolvendo esse recurso. A ideia de que o mercado se sobrepõe à política quando se trata de recursos energéticos faz parte de um discurso dominante do mainstream acadêmico e do establishment político-econômico liberal. Porém, o argumento encontra maiores limitações no caso do gás natural, em comparação com o mercado de petróleo.

Nesse sentido, a rede de gasodutos e as rotas de transporte energético por eles configuradas é parte essencial do Novo Grande Jogo, pois é através desse cenário que as potências aqui estudadas estão buscando consolidar seus interesses, sejam eles concorrentes ou cooperativos entre si. O Quadro 1 representa um esforço de mapear os principais gasodutos da região, apresentando as implicações geopolíticas de cada um. 


\section{Quadro 1}

Principais gasodutos da Eurásia

\begin{tabular}{|c|c|c|c|}
\hline Gasoduto & Ano & Descrição & Implicações geopolíticas \\
\hline BTC & $\begin{array}{l}\text { Concluído } \\
\text { em } 2006\end{array}$ & $\begin{array}{l}\text { Leva petróleo de } \\
\text { Baku, no Mar Cáspio, } \\
\text { até Ceyhan, passando } \\
\text { por Tbilisi }\end{array}$ & $\begin{array}{l}\text { Leva petróleo do Cáspio aos } \\
\text { mercados Ocidentais sem passar por } \\
\text { Rússia ou Irã. Por isso, é considerado } \\
\text { uma vitória dos EUA e seus aliados }\end{array}$ \\
\hline $\begin{array}{l}\text { BTE ou } \\
\text { Southern } \\
\text { Gas } \\
\text { Corridor }\end{array}$ & 2006 & $\begin{array}{l}\text { Paralelo ao BTC, } \\
\text { que leva gás natural } \\
\text { de Shah Deniz a } \\
\text { Erzurum }\end{array}$ & $\begin{array}{l}\text { Mesmos objetivos do BTC, porém } \\
\text { em relação ao gás natural. Também } \\
\text { os EUA saíram em vantagem, } \\
\text { enfraquecendo a Rússia, que } \\
\text { controlava a distribuição de gás }\end{array}$ \\
\hline Nabucco & $\begin{array}{l}\text { Negocia- } \\
\text { ções em } \\
\text { 2002/ } \\
\text { encerrado } \\
\text { em } 2013\end{array}$ & $\begin{array}{l}\text { Gás da Turquia à } \\
\text { Áustria, passando por } \\
\text { Bulgária, Romênia e } \\
\text { Hungria }\end{array}$ & $\begin{array}{l}\text { Projeto incentivado pelos EUA, } \\
\text { parte da UE e rival do South Stream. } \\
\text { Sua suspensão pode ser vista como } \\
\text { uma vitória dos interesses da Rússia }\end{array}$ \\
\hline $\begin{array}{l}\text { South } \\
\text { Stream }\end{array}$ & $\begin{array}{l}\text { Cons- } \\
\text { trução } \\
\text { começou } \\
\text { em 2012/ } \\
\text { suspensa } \\
\text { em } 2014\end{array}$ & $\begin{array}{l}\text { Transporte de } \\
\text { gás natural da } \\
\text { Rússia para a } \\
\text { Bulgária através } \\
\text { do Mar Negro e, } \\
\text { posteriormente, para } \\
\text { a Áustria }\end{array}$ & $\begin{array}{l}\text { Projeto russo concorrente } \\
\text { do Nabucco. Evita países } \\
\text { intermediários, como Ucrânia, e } \\
\text { aumenta a dependência dos países da } \\
\text { Ásia Central de Moscou. A própria } \\
\text { Rússia, porém, suspendeu o projeto } \\
\text { após as sanções subsequentes à } \\
\text { anexação da Crimeia }\end{array}$ \\
\hline $\begin{array}{l}\text { Nord } \\
\text { Stream }\end{array}$ & $\begin{array}{l}\text { Primeira } \\
\text { linha } \\
\text { inaugu- } \\
\text { rada em } \\
2011 \text { e a } \\
\text { segunda, } \\
\text { em } 2012\end{array}$ & $\begin{array}{l}\text { Transporte de } \\
\text { gás natural de } \\
\text { Vyborg (Rússia) } \\
\text { para Greifswald } \\
\text { (Alemanha) }\end{array}$ & $\begin{array}{l}\text { Tentativa da Rússia de evitar } \\
\text { países de trânsito, como a Ucrânia. } \\
\text { Aumenta a dependência europeia } \\
\text { do gás russo. A Alemanha aliou- } \\
\text { se completamente à Rússia neste } \\
\text { projeto, gerando desconfiança } \\
\text { dos demais países europeus, } \\
\text { que temem uma Alemanha } \\
\text { energeticamente autônoma em } \\
\text { relação à UE e, portanto, menos } \\
\text { empenhada em resolver novas } \\
\text { crises de fornecimento russo ao } \\
\text { bloco via Ucrânia. Ou seja, em um } \\
\text { possível conflito com a Rússia, a } \\
\text { Alemanha teria menos incentivos } \\
\text { para enfrentar Moscou, devido a seu } \\
\text { abastecimento privilegiado via Nord } \\
\text { Stream }\end{array}$ \\
\hline
\end{tabular}




\begin{tabular}{|c|c|c|c|}
\hline Gasoduto & Ano & Descrição & Implicações geopolíticas \\
\hline $\begin{array}{l}\text { Blue } \\
\text { Stream }\end{array}$ & $\begin{array}{l}\text { Inaugu- } \\
\text { rado em } \\
2003 / \\
\text { planejado } \\
\text { desde fim } \\
\text { da década } \\
\text { de } 1990\end{array}$ & $\begin{array}{l}\text { Leva gás natural da } \\
\text { Rússia diretamente à } \\
\text { Turquia }\end{array}$ & $\begin{array}{l}\text { Também evita os países de trânsito } \\
\text { e aumenta a dependência dos países } \\
\text { centro-asiáticos da Rússia }\end{array}$ \\
\hline $\begin{array}{l}\text { Trans-Cas- } \\
\text { pian Pipe- } \\
\text { line }\end{array}$ & $\begin{array}{l}\text { Ideia } \\
\text { iniciada } \\
\text { na década } \\
\text { de 1990/ } \\
\text { projeto } \\
\text { foi arqui- } \\
\text { vado em } \\
2000\end{array}$ & $\begin{array}{l}\text { Ligaria o } \\
\text { Turcomenistão } \\
\text { ao Azerbaijão, } \\
\text { passando por baixo } \\
\text { do Mar Cáspio, } \\
\text { com o objetivo } \\
\text { de se conectar ao } \\
\text { BTE, levando gás } \\
\text { turcomeno à Europa }\end{array}$ & $\begin{array}{l}\text { Tentativa de diminuir a dependência } \\
\text { dos países da Ásia Central dos dutos } \\
\text { controlados pela Rússia e de reduzir } \\
\text { a dependência Ocidental do gás } \\
\text { russo. Moscou é seu maior opositor. } \\
\text { O arquivamento do gasoduto em } \\
2000 \text { e a dificuldade de sua retomada } \\
\text { ilustram a influência russa. Um dos } \\
\text { entraves para seu avanço foram } \\
\text { as disputas territoriais na bacia } \\
\text { do Cáspio que, ao mesmo tempo } \\
\text { em que dificultam sua exploração, } \\
\text { também contribuem para que a } \\
\text { Rússia afaste tanto quanto possível } \\
\text { projetos ocidentais que diminuam } \\
\text { sua influência na Eurásia }\end{array}$ \\
\hline $\begin{array}{l}\text { Caspian } \\
\text { Pipeline } \\
\text { Consortium } \\
\text { (CPC) }\end{array}$ & $\begin{array}{l}\text { Inaugu- } \\
\text { rado em } \\
2001\end{array}$ & $\begin{array}{l}\text { Transporta petróleo } \\
\text { de Tengiz para } \\
\text { Novorossiisk, no Mar } \\
\text { Negro }\end{array}$ & $\begin{array}{l}\text { Vitória política dos EUA que, } \\
\text { através da Chevron, conseguiu } \\
\text { negociar o CPC. O oleoduto } \\
\text { fortalece a presença norte-americana } \\
\text { na região }\end{array}$ \\
\hline
\end{tabular}

Fonte: Elaborado pela autora.

A importância geopolítica da região também é ressaltada por Klare (2002, 49), para quem o Cáspio é parte do que o autor conceitua como "triângulo estratégico", cujas outras duas pontas seriam o Golfo Pérsico e o Mar do Sul da China. Segundo o autor, neste triângulo estariam as maiores reservas de petróleo do mundo, inúmeras disputas territoriais e interesses de segurança conflitantes de Estados poderosos. Este último fator está especialmente relacionado com a atuação de Rússia, EUA e China no Cáspio.

Rússia e Estados Unidos foram os dois primeiros atores do suposto Novo Grande Jogo. Com sua liderança historicamente consolidada na região, a Rússia possui uma relação muito próxima com os países do Cáspio. Esse relacionamento inclui a grande dependência de Moscou a que ficaram submetidos os Estados recém-soberanos em termos econômicos e de 
infraestrutura, porém envolve igualmente aspectos culturais e históricos, cuja origem encontra-se ainda no Império Russo.

A região da bacia do Mar Cáspio é parte do que a Rússia considera como seu Exterior Próximo, ou seja, uma zona de influência fundamental para a manutenção de seus interesses vitais. Além disso, Moscou precisa dos hidrocarbonetos provenientes dos países vizinhos para cumprir seus contratos de exportação de recursos energéticos, uma vez que a Rússia é um importante player nesse mercado global. Sua posição no contexto energético mundial é considerada estratégica para os dirigentes do Kremlin, pois lhe confere poder de barganha em outras questões da agenda internacional e traz vantagens ao país em termos de hierarquia global de poder. Assim, o lugar ocupado pela Rússia nesse contexto, tanto como produtora quanto como exportadora de hidrocarbonetos, ajuda a compreender a importância da região para a manutenção da posição russa no cenário energético e político internacional.

O primeiro e principal país a representar ameaça à influência russa na região foram os EUA, ator para quem segurança energética, política externa e grande estratégia estão intimamente atrelados, estando inclusive relacionados à própria defesa nacional, posicionando-se como preocupação prioritária e condicionando a política externa estadunidense. Assim, nos anos 1990, Washington viu na Ásia Central a possibilidade de integrar as recém-independentes economias locais ao mercado global de energia.

No entanto, essa estratégia esbarra na configuração das rotas de transporte regionais, as quais ainda dependem da Rússia. Por isso, o interesse de Washington na região precisa também ser analisado a partir de uma perspectiva ampliada para além da questão energética, pois a relevância do Cáspio na estratégia norte-americana relaciona-se com o objetivo maior de conter a projeção do poder russo, através da quebra de seu domínio logístico e da incorporação dos atores locais na ordem liberal.

Mais recentemente, a China também passou a ocupar espaço na Ásia Central. O fato de o país ter passado de exportador a um dos maiores importadores de recursos energéticos do mundo levou Pequim à necessidade de fazer parte do jogo geopolítico envolvendo as principais regiões produtoras. Seu objetivo estratégico central nesse contexto é diversificar suas fontes de energia para diminuir a dependência em relação às rotas marítimas controladas militarmente pelos EUA. Foi também com esse intuito que a China anunciou a construção de uma Nova Rota da Seda, projeto que envolve uma série de iniciativas de integração econômica que buscam ligar o leste asiático à Europa, passando, portanto, fundamentalmente pela Ásia Central.

É neste contexto que o país se volta ao Cáspio para diversificar seu fornecimento de energia. Sua presença na região tem se consolidado através 
do estabelecimento de acordos militares e investimentos locais e sua entrada no Jogo sinaliza ainda mais potencialidades para a região, que, além de ser importante fornecedora para a Europa, agora conta com as oportunidades trazidas pela crescente demanda asiática.

Um argumento frequentemente utilizado para explicar a presença destas potências na região é o de que um vácuo de poder - por conta da suposta fragilidade dos países da bacia - propiciaria oportunidade para a atuação externa. Brzezinski (1997) ilustra este argumento ao afirmar que a Eurásia, a exemplo da Europa, também possui seus Bálcãs. Estes eurasianos, porém, seriam diferenciados dos europeus por serem um vácuo de poder. $\mathrm{O}$ argumento é que, além de suas entidades políticas serem instáveis, elas convidam à intrusão de potências mais poderosas, em um cenário em que cada uma se oporá à dominação da região por outra. Essa ideia de vácuo de poder traçada pelo estrategista norte-americano na segunda metade da década de 1990 precisa, porém, ser problematizada, pois parte do ponto de vista das grandes potências. É importante que se deixe claro que, embora não seja o foco desta pesquisa, há fatores internos que pautam a busca pelos distintos interesses nacionais das repúblicas locais - países que não podem ser tratados como um mero espaço ou território.

Parte importante da imaginação geopolítica moderna de Agnew (2003, 74) é a obsessão com ganhos relativos através da competição entre Estados. Por isso, a busca pela primazia permanece importante na condução da política mundial:

Assim como as principais ideologias políticas fornecem o quadro competitivo para a competição política dentro de Estados, a imaginação geopolítica tem fornecido o quadro de referência para organizar atividades de Estado além deles. Lugares próximos e distantes podem ser classificados e relacionados à hierarquia de Estados: onde estão os principais competidores? Onde estão as melhores possibilidades para aprimorar a posição competitiva? Onde estão os principais desafios à hierarquia estabelecida? (Agnew 2003, 75, tradução nossa).

Focando nosso olhar no nível regional, encontramos também a competição pela primazia em termos hierárquicos de forma semelhante ao que Agnew nos apresenta. Há ali um claro encontro de interesses, muitas vezes sobrepostos, entre a potência hegemônica - EUA - e duas das principais revisionistas da estrutura do poder mundial - Rússia e China.

Nesse sentido, Labban (2009) argumenta que a atual política e estratégia dos EUA, e também da Rússia e da China, na região são dirigidas por realidades geopolíticas imediatas. $\mathrm{O}$ autor explica que a rivalidade geopolítica na Ásia Central hoje faz parte de um processo de eliminação de 
entidades geográficas que ameaçam a expansão do capitalismo - áreas alvo da expansão militar norte-americana.

Que a integração desses territórios, interstícios e espaços tenha tomado uma forma crescentemente militar não traduz necessariamente o processo em uma rivalidade geopolítica clássica baseada em Mackinder. Também não é o caso, no entanto, que a rivalidade geopolítica tenha se tornado algo do passado, substituída por formas mais benignas de competição geoeconômica e de relações multilaterais e cooperativas (Labban 2009, 3, tradução nossa).

Assim, para explicar a dinâmica política na Ásia Central no período pós-Guerra Fria, Labban (2009) propõe a ideia de hybrid geopolitics, na qual a expansão militar na região não opõe estratégias de controle territorial com o objetivo de assegurar o acesso a hidrocarbonetos, de contenção da Rússia, ou como parte da guerra ao terror - a estratégias de integração geoeconômica e cooperação multilateral, pois ambas fazem parte de um mesmo processo híbrido:

[… [O ] espaço geopolítico contemporâneo é irredutível a mapas divididos em círculos concêntricos, centrados em um lugar privilegiado pelos fatos objetivos da geologia e da geografia física. Em vez disso, é um espaço estruturado pela fusão de conjuntos de processos aparentemente opostos de exclusão e de contenção, através da expansão econômica, militar, ideológica sobreposta por processos de integração através dos mesmos processos de expansão. Este espaço geopolítico híbrido está repleto de tensões e contradições, algumas das quais são resolvidas através de mudanças a partir de um processo para outro, dependendo da conveniência política do momento e das relações inconstantes entre os competidores, em vez das propriedades físicas inerentes de determinadas regiões. (Labban 2009, 3, tradução nossa)

Compreender, portanto, a força de atração que a geopolítica exerce sobre governos e pesquisadores, especialmente quando se trata do Cáspio, é fundamental para entender as motivações que levam estas três potências - Rússia, EUA e China - a atuar na região. Esses incentivos resultam, muitas vezes, em interesses sobrepostos, configurando um ambiente conflitivo. Não obstante, esse padrão se mescla com o da cooperação, especialmente no que se refere a alianças para contrabalancear o poder do hegemon- muito à semelhança da "geopolítica híbrida" de Labban. 


\section{CONSIDERAÇÕES FINAIS}

Este artigo buscou compreender os motivos que atrelam o estudo da dinâmica que envolve a região do Cáspio à Geopolítica - abordagem que, em virtude de sua própria história, muitas vezes é malvista como marco teórico científico. Procuramos mostrar, contudo, que as características da região - especialmente no que se refere aos seus recursos energéticos - e a forma como os interesses das grandes potências têm, historicamente, se encontrado na região fazem da geopolítica ferramenta essencial para compreender o Cáspio.

O ressurgimento da geopolítica nas RI tem, muitas vezes, resultado em um uso banal do termo, seja na mídia ou mesmo na Academia. É preciso, contudo, recuperar a história dessa abordagem e compreender a polissemia que o conceito abarca. Neste esforço, a região do Cáspio, historicamente atrelada à Geopolítica desde os clássicos até os nossos dias, oferece ponto de partida importante. Ademais, é uma região na qual falar em ressurgimento é ilusório, uma vez que a geografia nunca deixou de desafiar os países locais.

O recorte temático em torno dos hidrocarbonetos da região evidencia ainda mais a presença da geopolítica e a dificuldade de superá-la mesmo com avanços em termos de cooperação regional e desenvolvimento de tecnologia. Da mesma forma como a história da Geopolítica está relacionada à região, também os recursos energéticos têm sido historicamente definidores da relação da região com o mundo, desde as primeiras descobertas de petróleo em Baku no século XIX até o emaranhado de gasodutos que ligam a região à Europa nos dias atuais.

\section{REFERÊNCIAS}

Adams, Terence. 2004. Caspian energy development. In: Akiner, Shirin. The Caspian Politics, energy and security. New York: Routledge, 79-94.

Agnew, John. 2003. Geopolitics: re-visioning world politics. 2. ed. Nova Iorque: Routledge.

Akiner, Shirin. 2004. Caspian intersections: contextual introduction. In: AKINER, Shirin. The Caspian Politics, energy and security. Nova Iorque: Routledge, 2-12.

Brzezinski, Zbigniew. 1997. The Grand Chessboard: American primacy and its geostrategic imperatives. Nova Iorque: Basic Books. 
Cohn, Marjorie. 2000. “Cheney's 'Black Gold': Oil Interests May Drive U.S. Foreign Policy”. Disponível em: <http://articles.chicagotribune.com/2000-08-10/ news/0008100507_1_caspian-oil-caspian-sea-gas-journal>. Acesso em: 15 out. 2016.

Cooley, Alexander. 2012. Great Games, Local Rules: The New Great Power Contest in Central Asia. Nova Iorque: Oxford University Press.

Dekmejian, R. Hrair e Hovann H Simonian. 2003. Troubled Waters: The Geopolitics of the Caspian Region. Nova Iorque: I.B. Tauris \& Co Ltd.

EIA (Energy Information Agency). 2013. Overview of oil and natural gas in the Caspian Sea region. Disponível em: <http://www.eia.gov/beta/international/regions-topics.cfm? RegionTopicID=CSR>. Acesso em: 14 set. 2016.

EIA (Energy Information Agency). 2015. International Rankings. Disponível em: $<$ http://www.eia.gov/beta/international/?src=-f3>. Acesso em: 14 set. 2016.

Fuser, Igor. 2013. Energia e Relações Internacionais. São Paulo: Saraiva.

Grygiel, Jakub J. 2006. Great powers and geopolitical change. JHU Press.

Kaplan, Robert D. 2013. A Vingança da Geografia: A construção do mundo geopolítico a partir da perspectiva geográfica. Rio de Janeiro: Elsevier.

Klare, Michael. 2002. Resource Wars: the new landscape of global conflict. Nova Iorque: Owl Books.

Klare, Michael. 2006. Sangre y Petróleo: Peligros y consecuencias de la dependencia del crudo. Barcelona: Ediciones Urano.

Klare, Michael. 2008. Rising Powers, Shrinking Planet: How scarce energy is creating a new world order. Oxford: Oneworld.

Kubicek, Paul. 2013. "Energy politics and geopolitical competition in the Caspian Basin.” Journal Of Eurasian Studies, [s.l.], 4 (2): 171-180.

Kucera, Joshua. 2014. After Summit, Caspian Sea Questions Linger. Disponível em: $<$ http://thediplomat.com/2014/10/after-summit-caspian-sea-questions-linger/>. Acesso em: 03 mai. 2016.

Labban, Mazen. 2009. "The Struggle for the Heartland: Hybrid Geopolitics in the Transcaspian." Geopolitics, [s.l.], v. 14, n. 1, p.1-25, 13.

Mackinder, Halford J. 1904. "The Geographical Pivot of History.” The Geographical Journal, [s.l.], 23 (4): 421-437. 
Mackinder, Halford J. 1919. Democratic ideals and reality: a study in the politics of reconstruction. Nova Iorque: Henry Holt And Company.

Milne, David. 2010. “America's 'intellectual' diplomacy.” International Affairs, [s.l.], $86(1):$ 49-68.

Naumkin, Vitaly. 2001. Russia's national security interests in the Caspian region. In: Chufrin, Gennady (Ed.). The Security of the Caspian Sea Region. New York: Oxford University Press, 119-135.

Newman, Sheila (Ed.). 2008. The Final Energy Crisis. 2. ed. Londres: Pluto Press.

Obama. [Discurso]. 2007. Obama: I've learned an immense amount from Dr. Brzezinski. Disponível em: <https://www.youtube.com/watch?v=ASlETExoTI>. Acesso em: 20 jun. 2016.

Republic of Kazakhstan. 2018. COMMUNIQUE of the $51^{\text {st }}$ Meeting of the Special Working Group on the Development of the Convention on the Legal Status of the Caspian Sea at the Level of Deputy Foreign Ministers of the Caspian Littoral States. Disponível em: <http://mfa.gov.kz/en/content-view/kommunike-51-go-zasedania-specialnoj-rabocej-gruppy-po-razrabotke-konvencii-o-pravovom-statusekaspijskogo-mora-na-urovne-zamestitelej-ministrov-inostrannyh-del-prikaspijskih-gosudarstv>. Acesso em: 30 mai. 2018.

Teixeira, Tatiana. 2009. "A Influência dos Think Tanks no Governo Bush e no Início da Era Obama.” In: II Simpósio De Pós-Graduação Em Relações Internacionais Do Programa "San Tiago Dantas" (Unesp, Unicamp E Puc/Sp), 2., São Paulo. Anais do II Simpósio de Pós-Graduação em Relações Internacionais do Programa "San Tiago Dantas" (Unesp, Unicamp e PUC/SP). São Paulo: PPGRI San Tiago Dantas, 1-19. Disponível em: <http://www.santiagodantassp.locaweb.com. $\mathrm{br} / \mathrm{br} / \mathrm{simp} /$ artigos2009/tatiana_teixeira.pdf $>$. Acesso em: 2 jul. 2016.

Van Apeldoorn, Bastiaan e Naná De Graaff. 2016. American Grand Strategy and Corporate Elite Networks: The Open Door since the end of the Cold War. Nova Iorque: Routledge.

Yakovenko, Alexander. 2014. Caspian Summit: Successful cooperation in 'oasis of peace'. Disponível em: <https://www.rt.com/op-edge/193960-caspian-summitsea-asia/>. Acesso em: 03 mai. 2016.

Zabortseva, Yelena Nikolayevna. 2012. "From the forgotten region to the great game region: On the development of geopolitics in Central Asia.” Journal Of Eurasian Studies, [s.l.], 3 (2): 168-176, jul. 


\section{NOTAS}

1. Termo utilizado para descrever a rivalidade entre grandes potências na região, especialmente entre Rússia, Estados Unidos e China.

2. Recursos que se situam em terra.

3. Recursos localizados no mar.

4. Tanto a produção quanto a exportação de seus recursos estavam prejudicadas em virtude das sanções econômicas aplicadas ao país pelo Ocidente, por conta de seu controverso programa nuclear.

5. Apesar de não ser um Estado limítrofe do mar Cáspio, o Uzbequistão possui maior parcela de território sob a bacia do que seu vizinho Turcomenistão. Segundo a EIA (2013), boa parte de seus recursos energéticos estão geologicamente localizados sob a bacia, porém menos de $1 \%$ da produção do país vem dessas reservas. Opta-se por incluí-lo como parte do que aqui se delimita como região do Cáspio, pois essa conjuntura reforça o argumento de que um dos elementos de atratividade internacional do Cáspio é justamente seu potencial, pois muitas reservas ainda se encontram inexploradas.

6. Convenciona-se neste trabalho que, quando a denominação "Cáspio" vier desacompanhada de mar, bacia ou região, o termo estará se referindo à região, conforme delimitado nesta seção.

7. Isso porque muitas vezes há confusão conceitual entre "geopolítica", "geoestratégia" e "geografia política". Ademais, mesmo o termo "geopolítica” remete a abordagens não apenas diferentes entre si, mas até mesmo opostas, já que o conceito adquire significados distintos se interpretado de acordo com a Geopolítica Clássica (composta por autores como Mackinder, Spykman e Mahan), a Geopolítica Crítica (sob forte influência marxista, especialmente após a publicação da obra "Geografia: isso serve em primeiro lugar para fazer a guerra", de Yves Lacoste, em 1976) ou sob a ótica da Geopolítica Contemporânea (com autores como John Agnew).

8. Como em Dekmejian e Simonian 2003; Newman 2008; Cooley 2012; Klare 2002, 2006, 2008; Zabortseva 2012.

9. Como exemplo, pode-se citar a influente empresa de inteligência norte-americana Stratfor, que possui foco explicitamente geopolítico. Dentre seus membros estão George Friedman, fundador da empresa, e Robert D. Kaplan, autor de "A Vingança da Geografia: A construção do mundo geopolítico a partir da perspectiva geográfica”.

10. O termo foi cunhado em 1899 pelo sueco Rudolf Kjellén.

11. Sobre este assunto, ver Van Apeldoorn e De Graaff 2016; Milne 2010; Teixeira 2009.

12. Mackinder cunhou o conceito de Ilha Mundial, que seria a soma do continente Eurasiano com o Africano. A ideia de Brzezinski segue essa mesma linha. 


\section{RESUMO}

O artigo trata da relação entre a Geopolítica e a região do Cáspio, com enfoque em seus recursos energéticos. Com este fim, o trabalho problematiza a ideia do retorno da geopolítica, buscando evidenciar como, na região, a abordagem sempre imperou, tanto como lente analítica quanto como framework para a política das grandes potências.

Palavras-chave: Geopolítica; Energia; Eurásia; Cáspio.

\section{ABSTRACT}

The article assesses the relation between Geopolitics and the Caspian region, with emphasis on its energy resources. To that end, the article problematizes the idea of the return of geopolitics, by indicating that, in the region, the approach has always been dominant, both as an analytical lens and a framework for great power politics.

Keywords: Geopolitics; Energy; Eurasia; Caspian. 